University of Nebraska - Lincoln

DigitalCommons@University of Nebraska - Lincoln

Faculty Publications from the Harold W. Manter Laboratory of Parasitology

2-1988

\title{
Phylogenetic Analysis of the Bunocotylinae Dollfus, 1950 (Digenea: Hemiuridae)
}

Virginia León-Règagnon

Universidad Nacional Autónoma de México

Gerardo Pérez Ponce de León

Universidad Nacional Autónoma de México, ppdleon@servidor.unam.mx

Daniel R. Brooks

University of Toronto,dnlbrooks@gmail.com

Follow this and additional works at: https://digitalcommons.unl.edu/parasitologyfacpubs

Part of the Parasitology Commons

León-Règagnon, Virginia; Pérez Ponce de León, Gerardo; and Brooks, Daniel R., "Phylogenetic Analysis of the Bunocotylinae Dollfus, 1950 (Digenea: Hemiuridae)" (1988). Faculty Publications from the Harold W. Manter Laboratory of Parasitology. 288.

https://digitalcommons.unl.edu/parasitologyfacpubs/288

This Article is brought to you for free and open access by the Parasitology, Harold W. Manter Laboratory of at DigitalCommons@University of Nebraska - Lincoln. It has been accepted for inclusion in Faculty Publications from the Harold W. Manter Laboratory of Parasitology by an authorized administrator of DigitalCommons@University of Nebraska - Lincoln. 


\title{
PHYLOGENETIC ANALYSIS OF THE BUNOCOTYLINAE DOLLFUS, 1950 (DIGENEA: HEMIURIDAE)
}

\author{
Virginia León-Règagnon, Gerardo Pérez-Ponce de León ${ }^{\star}$, and Daniel R. Brooks \\ Center for Historical Ecology and Biodiversity, Department of Zoology, University of Toronto, 25 Harbord St. Toronto, Ontario, Canada M5S 3G5
}

\begin{abstract}
The phylogenetic analysis of the 16 recognized genera in the Bunocotylinae, based upon 30 morphological transformation series, produced 2 most parsimonious trees, each with a consistency index of 0.62 . The monophyly of the group is supported by 6 synapomorphies. Ahemiurus, Aphanuroides, Aphanurus, Myosaccium, and Indoderogenes separate independently in the basal part of the tree. Saturnius and Bunocotyle separate next, forming a clade. Machidatrema, Duosphincter, Theletrum, and Monolecithotrema separate independently; and in the most derived part of the tree Opisthadena + Neopisthadena + Mitrostoma, Genolinea, and Neotheletrum grouped together form a clade. Optimization of hosts and geographic distribution onto the 2 most parsimonious trees suggests that the bunocotylines originated from an ancestor that was host specific to fishes of the Clupeidae and was distributed in the Tethys Sea.
\end{abstract}

Digeneans of the order Hemiuriformes (sensu Brooks et al., 1985) are 1 of the most common and diverse groups parasitizing marine fish. One of the the most diverse and widely distributed hemiuriform taxa is the Buonocotylinae, generally considered a member of the Hemiuridae. Like that of most digeneans, the classification of the bunocotylines has been unstable historically. Yamaguti (1971) included 4 genera in the subfamily: Bunocotyle Odhner, 1928, Saturnius Manter, 1969, Theletrum Linton, 1910, and Pseudobunocotyla Yamaguti, 1935. Gibson and Bray (1979) established the Bunocotylidae and subdivided it into 4 subfamilies: Bunocotylinae, comprising Bunocotyle Odhner, 1928 and Saturnius Manter, 1969; Aphanurinae, comprising Aphanurus Looss, 1907, Ahemiurus Chauhan, 1954, Aphanuroides Nagaty and Abdel-Aal, 1962, Duosphincter Manter and Pritchard, 1960, and Myosaccium Montgomery, 1957; Opisthadeninae, comprising Opisthadena Linton, 1910, Genolinea Manter, 1925, Mitrostoma Manter, 1954, Neotheletrum Gibson and Bray, 1979; and Theletrinae, comprising Theletrum Linton, 1910, Indoderogenes Srivastava, 1937 and Monolecithotrema Yamaguti, 1970. In their evolutionary scenario, Gibson and Bray (1979) depicted the Bunocotylidae as the sister group of the Hemiuridae. Brooks et al. (1985) provided the first phylogenetic systematic analysis of the group, using the taxa and characters listed by Gibson and Bray (1979). The phylogenetic study indicated that Gibson and Bray's conception of the Hemiuridae was paraphyletic if the Bunocotylidae were excluded from it; hence, Brooks et al. (1985) returned the Bunocotylidae sensu Gibson and Bray to subfamilial status within a monophyletic Hemiuridae. The phylogenetic analysis of the Bunocotylinae, however, failed to provide any synapomorphies supporting the monophyly of that particular group. Since Gibson and Bray's (1979) study, 3 additional genera belonging to this group have been established: (1) Neopisthadena Machida, 1980; (2) Neoaphanurus Tang, Shi, Cao, Guan and Pan, 1983; and (3) Machidatrema León-Règagnon, 1997.

In this study, the monophyly of the Bunocotylinae is assessed and a phylogenetic hypothesis for the genera included in the group is proposed.

Received 27 January 1997; revised 20 June 1997; accepted 20 June 1997.

* Laboratorio de Helmintología, Instituto de Biología. Universidad Nacional Autónoma de México.

\section{MATERIALS AND METHODS}

\section{Specimens examined}

All available literature as well as the following museum specimens were examined for comparison (accession numbers in parentheses): Colección Nacional de Helmintos, Instituto de Biología, UNAM, México (CNHE): Genolinea laticauda (807); Myosaccium ecaude (2791-2797); Neotheletrum gravidum (999); Neotheletrum lissosomum (1517); Opisthadena dimidia (899, 2631, 2632, 898, 1379, 1483); Parahemiurus merus (2633-2641). United States National Parasite Collection (USNPC): Duosphincter zancli (39167); Genolinea dactylopargi (49151); Genolinea anura (49177); Genolinea montereyensis (36952); Genolinea noblei (60290); Machidatrema frontilatum (63328); Machidatrema kyphosi (63748); Mitrostoma nothoteniae (49150); Myosaccium ecaude (38185); Myosaccium opisthonemae (39393); Neotheletrum gravidum (9369), $N$. lissosomum (9368), Neotheletrum magnasaccum (39500), Neotheletrum pomacentri (60292); O. dimidia (8489); Opisthadena bodegensis (37338); Opisthadena kyphosi (63790); Saturnius segmentatus (71219); Saturnius maurepasi (73270); Saturnius mugilis (63747); Saturnius belizensis (74167); Saturnius papernai (73271); Theletrum fustiforme $(8500,39392)$. Harold W. Manter Laboratory (HWML): N. lissosomum (120, 121); N. gravidum (122, 123, 124, 125); M. frontilatum (631); T. fustiforme (473, 124642). Meguro Parasitological Museum (MPM): Aphanurus harengulae (22700); Aphanurus caesionis (22703); Aphanurus dorosomatis (22702); M. kyphosi (15184); Monolecithotrema kala (15187); O. kyphosi (15245); S. mugilis (15180). National Science Museum, Tokyo, Japan (NSMT): M. kyphosi (Pl3161a, Pl2292a); Machidatrema chilostoma (Pl2292b, Pl2234a); Machidatrema akeh (Pl3184); M. kala (Pl2140, Pl3177, Pl3794); Neopisthadena habei (Pl2293); O. dimidia (Pl2234b). It was impossible for us to examine specimens from Aphanuroides, Indoderogenes, Ahemiurus, and Bunocotyle, because these are monotypic and in the original descriptions it is not indicated if types were deposited in a collection; in these cases, available literature was consulted.

\section{Phylogenetic analyses}

Phylogenetic analyses were performed using the methods of phylogenetic systematics (Hennig, 1966; Wiley et al., 1991). Results were confirmed quantitatively using the PAUP (phylogenetic analysis using parsimony) computer program version 3.1.1. (Swofford, 1993), run on a Macintosh Power Mac 8500 . The following options were specified: (1) characters 19 and 25 ordered; (2) out groups: plesiomorphic conditions determined using the out-group method (Watrous and Wheeler, 1981; Maddison et al., 1984) by the states observed in the genera Hemiurus, Parahemiurus, and Anahemiurus (Hemiurini), recognized as the sister group of bunocotylids (Gibson and Bray, 1979; Brooks et al., 1985); (3) optimization: acctran, deltran; and (4) tree-building algorithms: branch and bound.

\section{Character argumentation}

We used the following characters and their states in phylogenetic analysis. Characters are listed in order of their appearance in Table I. 0 $=$ plesiomorphy; $1,2=$ apomorphies . 
TABLE I. Data matrix for phylogenetic analysis of Bunocotylinae genera.*

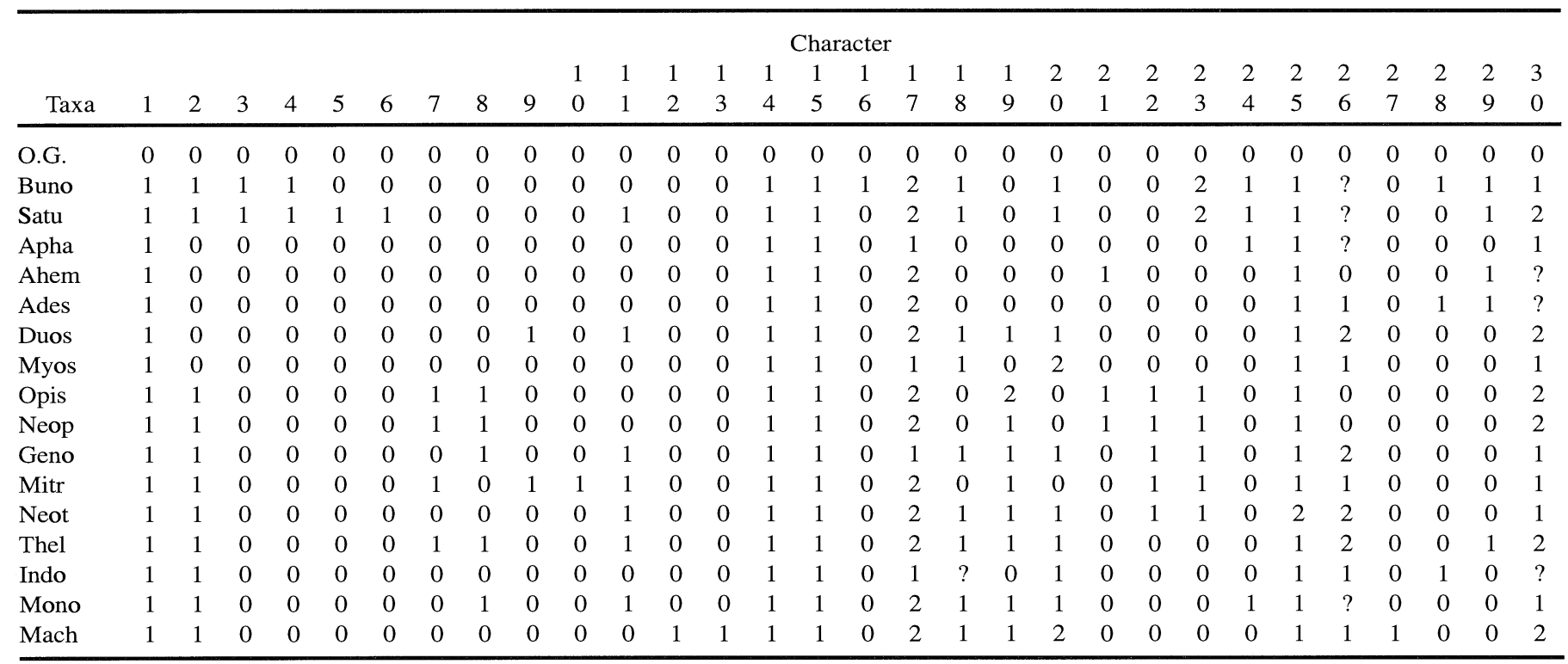

* Characters are numbered as in the text; for description of characters and polarity arguments, see text. $0=$ plesiomorphic condition; $1,2=$ apomorphic conditions; ? $=$ unknown. O.G. (out group) = Hemiurini (Hemiurus, Parahemiurus, Anahemiurus); Buno = Bunocotyle; Satu = Saturnius; Apha = Aphanurus; Ahem = Ahemiurus; Ades = Aphanuroides $;$ Duos = Duosphincter $;$ Myos = Myosaccium; Opis = Opisthadena $;$ Neop = Neopisthadena $;$ Geno $=$ Genolinea $;$ Mitr $=$ Mitrostoma $;$ Neot $=$ Neotheletrum; Thel = Theletrum; Indo = Indoderogenes; Mono = Monolecithotrema $;$ Mach = Machidatrema.

(1) Ecsoma. The absence of an ecsoma is plesiomorphic for all digeneans. An ecsoma is present in all members of the Hemiuridae except Bunocotylinae and is unique among digeneans in that family. In order to include the Bunocotylinae in the Hemiuridae, some authors have described vestigial ecsomas, but our examination of specimens and illustrations from the literature leads us to believe that at times the large excretory pore typical of the bunocotylines has been confused with a small invaginated ecsoma. Phylogenetic analysis of the hemiuriforms indicates that its absence is apomorphic within the Hemiuridae; we therefore code this apparent secondary loss as apomorphic in this analysis. $0=$ present; 1 = absent.

(2) Cuticular plications. The absence of cuticular plications is ple-

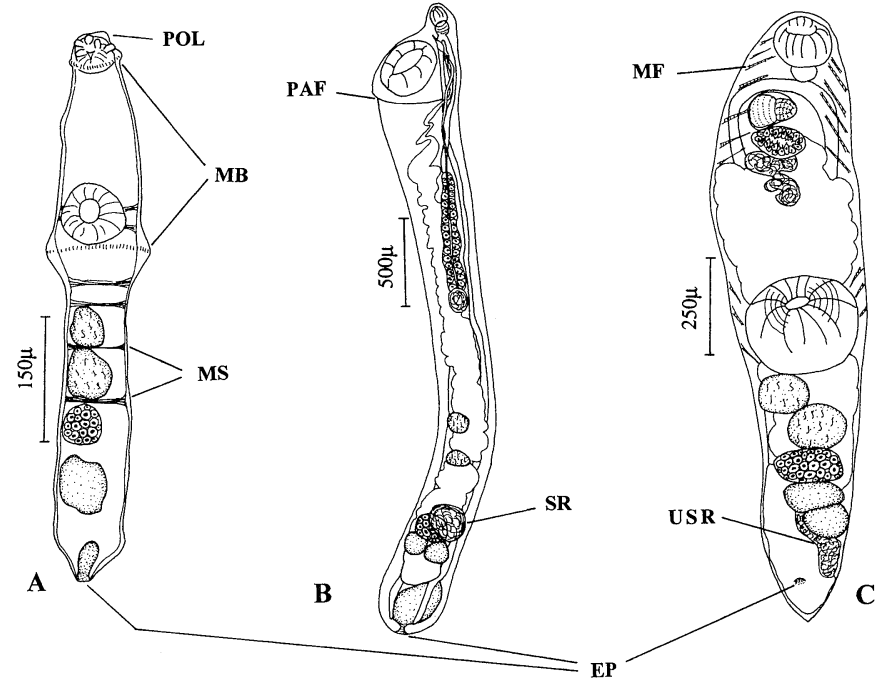

FIGURE 1. Selected structures of bunocotylines. A. Saturnius sp. B. Opisthadena sp. C. Machidatrema sp. EP = excretory pore; $\mathrm{MB}=$ muscular belt; MF = muscle fibers; MS = muscular septa; PAF = postacetabular fold; $\mathrm{POL}=$ preoral lobe; $\mathrm{SR}=$ seminal receptacle; USR $=$ uterine seminal receptacle. siomorphic for all digeneans. Phylogenetic analysis of the hemiuriforms indicates that its absence is apomorphic within the Hemiuridae; we therefore code this apparent secondary loss as apomorphic in this analysis. $0=$ present; $1=$ absent.

(3) Muscular belt surrounding body at level of acetabulum (Fig. 1). $0=$ absent; 1 = present. This structure, present in Bunocotyle and Saturnius, differs from the postacetabular fold described in Opisthadena, Neopisthadena, Theletrum, and Mitrostoma, even though the same term, "postacetabular ridges," has been applied to both conditions.

(4) Muscular belt surrounding body at level of oral sucker (Fig. 1). $0=$ absent; 1 = present.

(5) Internal muscular septa (Fig. 1). $0=$ absent; $1=$ present.

(6) Muscular papillae on oral sucker. $0=$ absent; $1=$ present.

(7) Postacetabular fold (Fig. 1). 0 = absent; 1 = present.

(8) Cuticular papillae. $0=$ absent; $1=$ present.

(9) Muscular sphincter in acetabulum. $0=$ absent; $1=$ present.

(10) Preacetabular pit. $0=$ absent; $1=$ present.

(11) Preoral lobe. 0 = absent; 1 = present.

(12) Strong muscle fibers in forebody (Fig. 1). $0=$ absent; $1=$ present.

(13) Excretory pore position (Fig. 1). 0 = terminal or subterminal; 1 $=$ far from the posterior end, ventral.

(14) Excretory pore size. $0=$ inconspicuous; $1=$ large.

(15) Excretory vesicle. $0=$ elongate; $1=$ bulbous.

(16) Intestinal ceca. $0=$ ending separated; $1=$ united

(17) Testes position. $0=$ symmetric; $1=$ oblique; $2=$ tandem.

(18) Seminal vesicle position. $0=$ postacetabular; $1=$ preacetabular.

(19) Seminal vesicle shape. $0=$ subspherical; $1=$ elongate; $2=$ elongate, coiled, enclosed in a seminal sac.

(20) Pars prostatica. $0=$ long; $1=$ short; 2 = prostatic vesicle.

(21) Ejaculatory duct. $0=$ absent; $1=$ present.

(22) Uterine seminal receptacle (Fig. 1). $0=$ present; $1=$ absent. The seminal fluid storage structures have been used as important taxonomic characters in this group. In most of the hemiuriforms, the proximal end of the uterus functions as a seminal receptacle (uterine seminal receptacle). In some genera of bunocotylines a specialized structure has developed to fulfill that function.

(23) Structures derived from Laurer's canal (Fig. 1). 0 = Juel's organ; $1=$ seminal receptacle; 2 = Laurer's canal derivatives lacking. Laurer's canal is present in some groups of hemiuriforms, including the Azygi- 
idae, Accacoeliidae, and Hirudinellidae. In others, such as the Hemiuridae, this structure has modified into a Juel's organ, which is glandular, has a central vesicle where it has been proposed that excess seminal and vitelline material is stored, degraded, and reabsorbed, and which has no connection to the exterior. In some Bunotocylinae, the Juel's organ has been modified further, losing its glandular nature and becoming a seminal receptacle that replaces the uterine seminal receptacle. Bunocotyle and Saturnius lack Juel's organ or seminal receptacle.

(24) Number of vitelline masses. $0=2 ; 1=1$. In some species of bunocotylids 3 vitelline masses have been described, but when examining the specimens and drawings, we noticed that the anterior mass was strongly bilobed, which was misinterpreted as the existence of 3 masses.

(25) Shape of vitelline masses. $0=2$ slightly lobed masses, with 3 and 4 lobes respectively; $1=2$ entire masses. In 2 Machidatrema species vitelline masses may present slightly irregular margins; 2 = bilobed anterior mass.

(26) Vitelline mass position. $0=$ symmetric; $1=$ oblique; $2=\tan$ dem.

(27) Hermaphroditic duct. $0=$ not divided; $1=$ divided in 2 regions In members of Machidatrema, the distal region of the hermaphroditic duct is strongly muscular and may be extruded as a temporary sinus organ. This differs from the genital atrium described by Gibson and Bray (1979), for several species of hemiurids.

(28) Sinus sac. $0=$ present; $1=$ absent.

(29) Sinus organ. $0=$ presence of a temporary sinus organ; $1=$ absent.

(30) Genital pore location. $0=$ at level of oral sucker; $1=$ at level of pharynx; 2 = posterior to pharynx.

\section{RESULTS}

In this analysis, all 14 genera in the Bunocotylinae sensu Brooks et al. $(1985,1989)$ and the Bunocotylidae sensu Gibson and Bray (1979), as well as Neopisthadena and Machidatrema were considered valid. In the original diagnosis of the Neoaphanurus, Tang et al. (1983) reported a seminal vesicle occupying the posterior region of the body and a seminal receptacle. Examination of original description and drawings showed that most of the traits of these specimens match with those of Aphanurus, with the exception of the 2 aspects mentioned above. Within the Hemiuridae, the seminal vesicle is always pretesticular; for this reason we consider that the structure described as a seminal vesicle to be actually a coiled uterine seminal receptacle (both structures look similar when filled with sperm). A uterine seminal receptacle is normally associated with a Juel's organ and not with a seminal receptacle, and these 2 structures may easily be confused with each other. We believe this species belongs to the genus Aphanurus, but as the specimens were not available, we consider this taxon as a species inquirendae and did not include it in the analysis.

The phylogenetic analyses of the 16 taxa we considered valid produced 2 equally parsimonious trees, with a consistency index of 0.62 ( 58 transformations to 36 possible apomorphies), excluding character 29 from the analysis (Fig. 2). This character (the presence or the absence of a sinus organ) was originally included in the analysis, producing 10 equally parsimonious trees, each with a consistency index of 0.597. Two of those trees correspond with the 2 trees shown in Figure 2. The other 8 differed in the position of the 5 basal genera (Ahemiurus, Aphanuroides, Aphanurus, Myosaccium, and Indoderogenes). In 6 of the trees, Ahemiurus and Aphanuroides formed a clade as the sister group of the rest of the taxa, supported only by the lack of a sinus organ. The sinus organ is a very difficult structure to be observed when retracted. We were unable to examine specimens of the relevant genera, and original descriptions are very poor, so we excluded this character from the analysis because it is possible that the sinus organ was present but was not observed in those genera where it has been described as absent. When this character was excluded, the relationships of those 5 basal taxa were highly stable, and the 2 resulting trees differed only in the position of the Genolinea in relation to the clade Opisthadena + Neopisthadena + Mitrostoma and Neotheletrum. This suggests to us that Genolinea, as presently constituted, may not be monophyletic (see PérezPonce de León and Brooks [1995] for a similar situation involving Pleurogonius within the Pronocephalidae).

\section{DISCUSSION}

The monophyly of the Bunocotylinae is supported by the following synapomorphies: 1 (lack of ecsoma), 14 (large excretory pore), 15 (bulbous excretory vesicle), 17 (testes in tandem), 25 (entire vitelline masses), and 30 (genital pore at the level of pharynx or posterior to it). The consistency index $(0.621)$ is lower than those obtained for other groups of digeneans $(0.71$ for the general Digenea data matrix; Brooks and McLennan, 1993a, 1993b) and particular groups of bunocotylids (León-Règagnon et al., 1996; León-Règagnon, 1997). A high proportion of the homoplasy in the group is concentrated in the clade Mitrostoma + Neopisthadena + Opisthadena. When this group is removed from the analysis, the consistency index rises to 0.74 , but whether or not these taxa are included, the relationships among all other members of the subfamily remained consistent. This suggests that the clade Mitrostoma + Neopisthadena + Opisthadena exhibits an unusual amount of homoplasy at the generic level. At the specific level, however, this pattern is not repeated (see León-Règagnon et al., 1996). The proportion of evolutionary losses observed in our analyses $(15.5 \%)$ is comparable to those reported by Brooks and McLennan (1993a, 1993b) (12\%), supporting their conclusion that parasites do not show high levels of evolutionary simplification.

The polytomy formed by the groups Neotheletrum, Genolinea, and Opisthadena + Neopisthadena + Mitrostoma is probably due to extreme interspecific morphological variability among members of Genolinea, which is the bunocotyline genus with the largest number of nominal species, many of which have been poorly described. A phylogenetic analysis of the species of this genus would help to solve this polytomy. Comparing the generic grouping in our analysis with those proposed by Gibson and Bray (1979) (Fig. 3), we note that the groups formed by Bunocotyle + Saturnius (Bunocotylinae sensu Gibson and Bray, 1979) and Opisthadena + Mitrostoma + Genolinea + Neotheletrum (Opisthadeninae sensu Gibson and Bray, 1979) were maintained. Monolecithotrema, and Theletrum (members of the Theletrinae sensu Gibson and Bray, 1979) are paraphyletic to the clade formed by Opisthadena + Neopisthadena + Mitrostoma + Genolinea + Neotheletrum. Duosphincter was grouped in the Aphanurinae, which, according to their analysis is paraphyletic at the base of the tree, but our analysis places it as the sister group of the clade Opisthadena + Neopisthadena + Mitrostoma + Genolinea + Neotheletrum, Monolecithotrema and Theletrum, which are nonbasal members of the subfamily. The clade Bunocotyle + Saturnius is the sister group of those taxa plus Machidatrema, instead of being the 


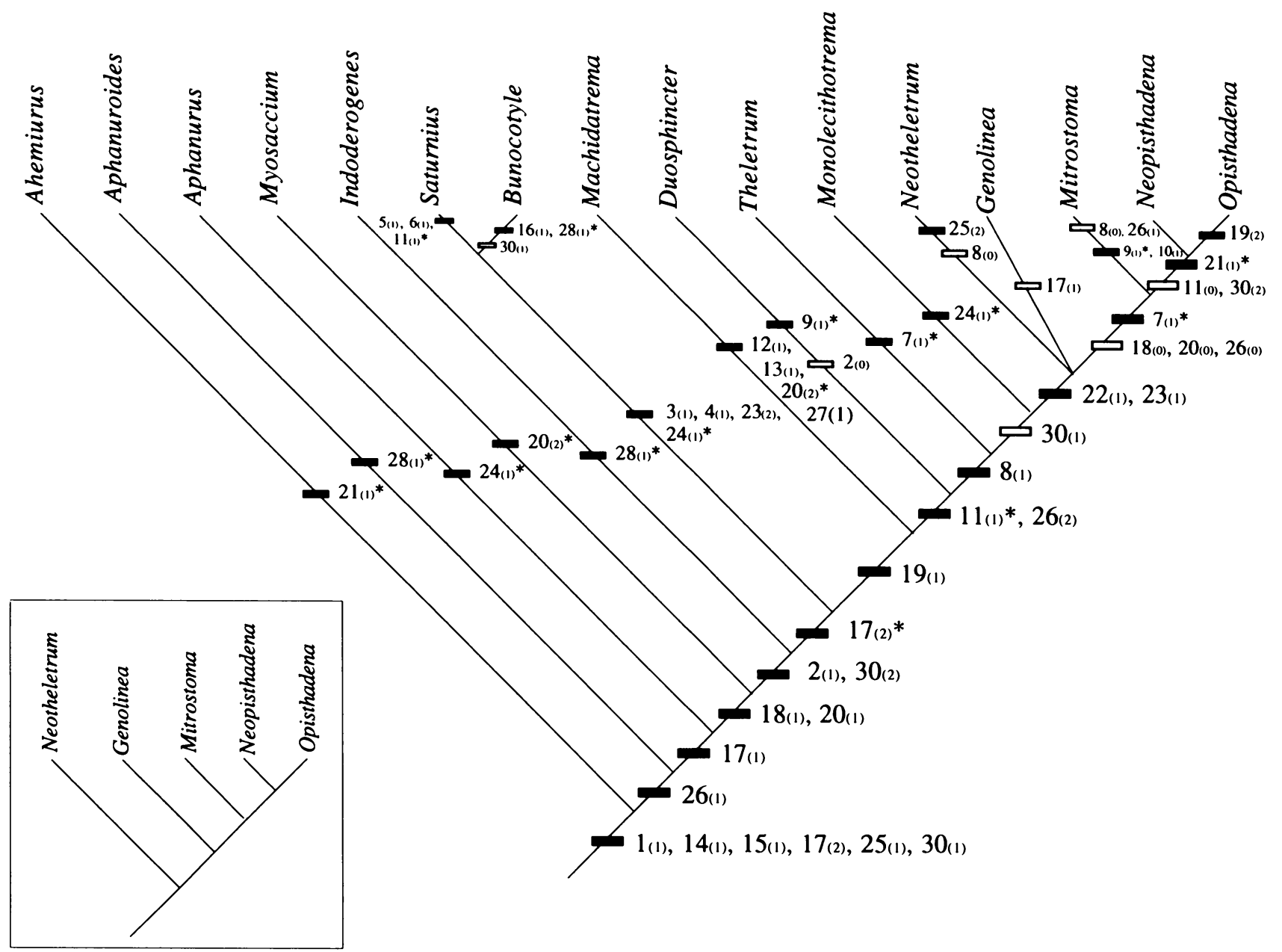

FIGURE 2. Phylogenetic trees for genera in the subfamily Bunocotylinae. Large tree is the consensus tree and also 1 of the 2 equally parsimonious trees. Insert is alternative equally parsimonious tree. Numbers accompanying slash marks on tree indicate apomorphic traits supporting each branch (character number followed by character state in parentheses; empty slashes indicate reversals; * $=$ homoplasy). For character identity refer to text. Characters 20 and 26 are ambiguous and can be optimized in more than 1 way without changing the topology of the tree.

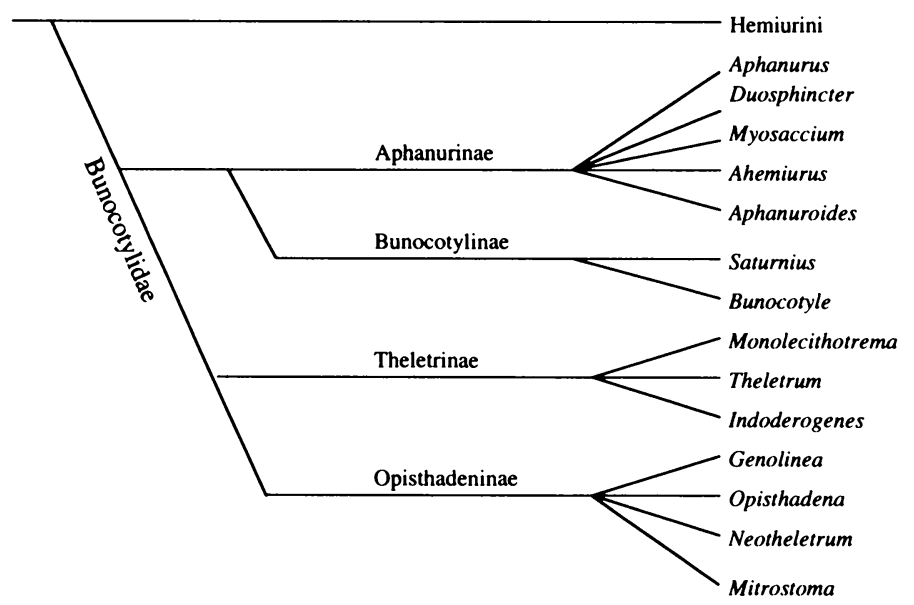

FIGURE 3. Evolutionary scheme of bunocotylines proposed by Gibson and Bray (1979). sister group of the Aphanurinae (sensu Gibson and Bray, 1979). Our analysis supports the polarization of the Laurer's canal derivatives proposed by Gibson and Bray (1979) (Juel's organ may have given rise to a seminal receptacle or may have been lost).

On the contrary, it does not support the idea that there is a linear tendency toward reduction in body size, and this was the primary reason some of the groups proposed by Gibson and Bray were not maintained. This is not surprising, because the concept of linear macroevolutionary trends is a legacy of the orthogenetic, rather than Darwinian, evolutionary ideas that pervaded parasitological systematics during the period 18901940, and which continue to be expressed today (see Brooks and McLennan, 1993a). The phylogenetic hypothesis for the Hemiuridae proposed by Brooks et al. $(1985,1989)$ was based upon the same characters used by Gibson and Bray (1979) in their diagnoses. The difference in results is due to the use of phylogenetic methods by Brooks et al. (1985) and of intuition by Gibson and Bray (1979). We have noticed that the monophyly of some of the taxa are supported by characters that are greatly variable within them. It is necessary to perform a phy- 


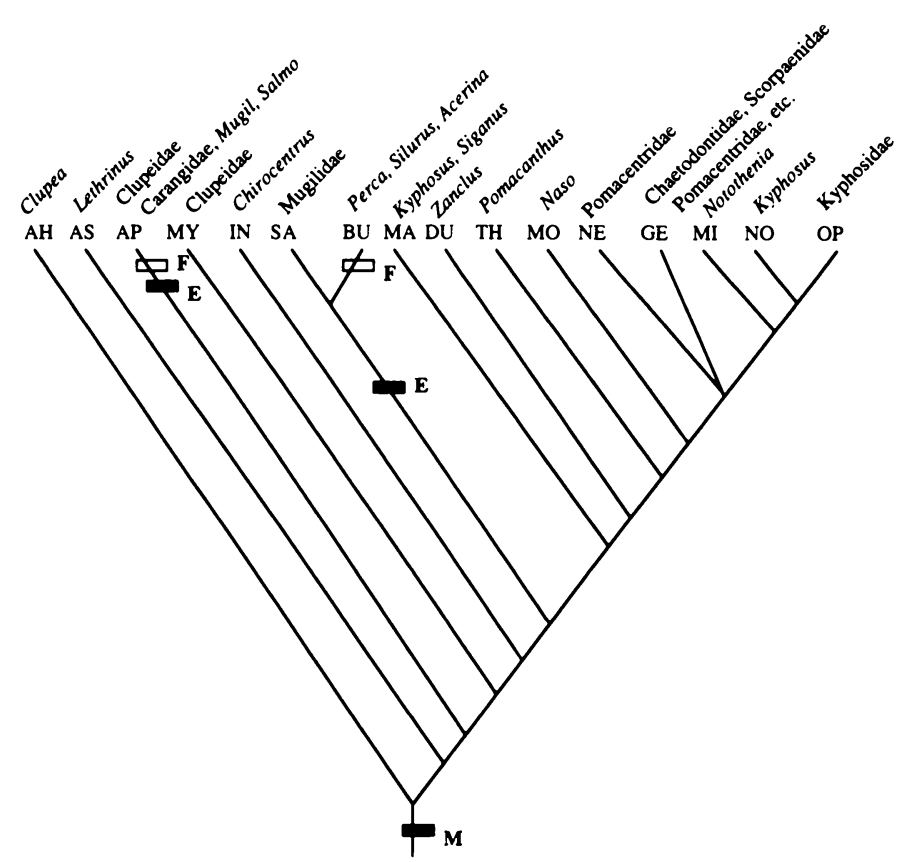

FIGURE 4. Definitive host group and primary habitat $(M=$ marine; $E=$ estuarine; $F=$ freshwater) optimized onto phylogenetic tree for bunocotyline genera. The tree supports 2 separate invasions to estuarine and then freshwater habitats. $\mathrm{AH}=$ Ahemiurus; $\mathrm{AS}=$ Aphanuroides; $\mathrm{AP}=$ Aphanurus $; \mathrm{MY}=$ Myosaccium $; \mathrm{IN}=$ Indoderogenes $; \mathrm{SA}=$ Saturnius $; \mathrm{BU}=$ Bunocotyle $; \mathrm{MA}=$ Machidatrema $; \mathrm{DU}=$ Duosphinc ter $; \mathrm{TH}=$ Theletrum $; \mathrm{MO}=$ Monolecithotrema $; \mathrm{NE}=$ Neotheletrum; $\mathrm{GE}=$ Genolinea $; \mathrm{MI}=$ Mitrostoma $; \mathrm{NO}=$ Neopisthadena $; \mathrm{OP}=$ Opisthadena.

logenetic study of particular genera and species to obtain a classification scheme that reflects the genealogy of the taxa of this controversial group of digeneans.

Optimizing the definitive host taxa and habitat (marine, estuarine, or freshwater) onto the consensus tree (doing the same onto the alternative tree does not make any difference in the interpretation of results) (Fig. 4), we notice that the group is predominantly and primitively marine, and that most of the basal genera (Ahemiurus, Aphanurus, Myosaccium) inhabit mostly fishes of the family Clupeidae, the same as the outgroups. Species of Aphanurus have occasionally been recorded parasitizing euryhaline fish in Mugil and Salmo, possibly indicating some host-switching events coupled with habitat change. Machidatrema and its sister group parasitize a wide variety of perciform fishes. Only Opisthadena and Neopisthadena show pronounced host specificity, parasitizing only fishes of the Kyphosidae (León-Règagnon et al., 1996, 1997). The tree indicates that the clade Bunocotyle + Saturnius separated from its sister group as the result of a host-switching event associated with a change in habitat, from marine to estuarine or freshwater, in a manner similar to that observed in Aphanurus. The species of Saturnius are specific to the euryhaline Mugil, whereas species of Bunocotyle apparently colonized freshwater fishes.

Optimizing geographic distributions on the phylogenetic tree (Fig. 5) demonstrates that all basal groups, except Myosaccium and Bunocotyle, are restricted to Arabian Sea, Arabian Gulf, and Mediterranean Sea. Saturnius has a wide geographic distribution, corresponding to that of its fish hosts (Mugil spp.).

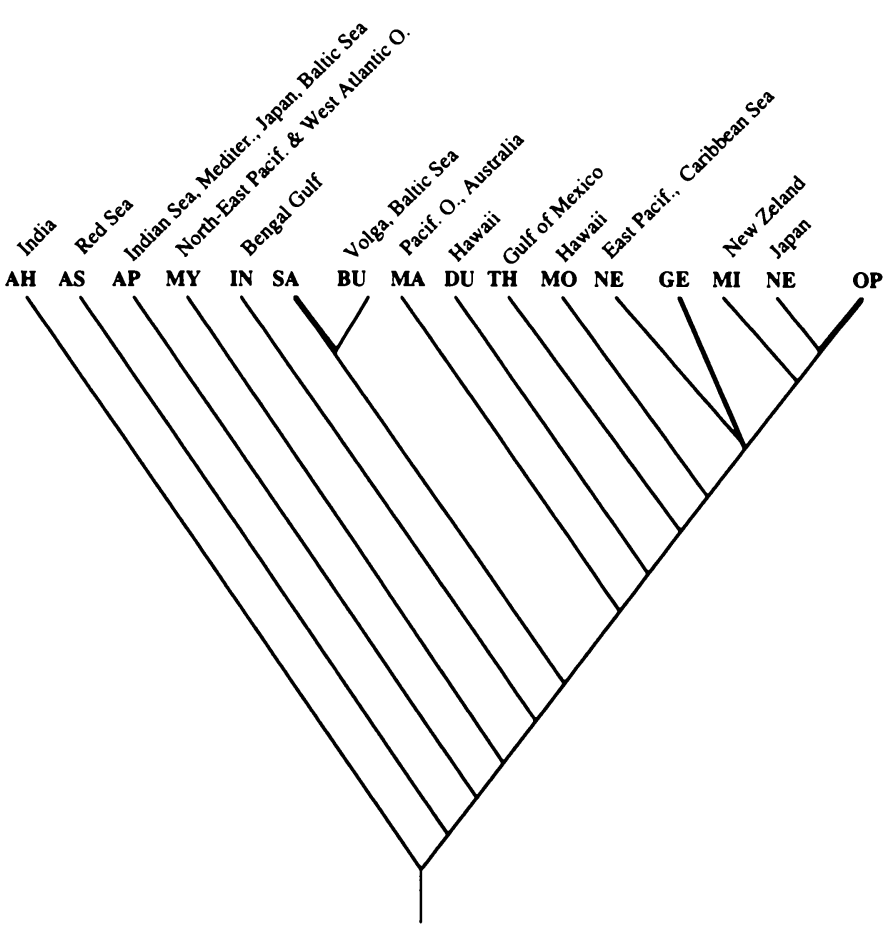

Figure 5. Optimization of geographical distribution onto phylogenetic tree of genera of Bunocotylinae. Bold lines indicate widely distributed taxa (Pacific Ocean, Australia, Indian Ocean, Mediterranean, and Gulf of México). AH = Ahemiurus; AS = Aphanuroides; AP = Aphanurus; $\mathrm{MY}=$ Myosaccium $; \mathrm{IN}=$ Indoderogenes; $\mathrm{SA}=$ Saturnius; $\mathrm{BU}=$ Bunocotyle; $\mathrm{MA}=$ Machidatrema; $\mathrm{DU}=$ Duosphincter $; \mathrm{TH}=$ Theletrum; $\mathrm{MO}=$ Monolecithotrema $; \mathrm{NE}=$ Neotheletrum $; \mathrm{GE}=$ Genolinea $;$ $\mathrm{MI}=$ Mitrostoma $; \mathrm{NO}=$ Neopisthadena $; \mathrm{OP}=$ Opisthadena .

Machidatrema and its sister group also have a wide geographic distribution (east and west Pacific, New Zealand, Australia, the Gulf of México, Caribbean Sea, and Arabian Sea). The distribution of basal groups in the vicinity of the Arabian Sea, Arabian Gulf, and Mediterranean Sea is consistent with an hypothesis of origin in the Tethys Sea. Evolutionary radiation into the Pacific Ocean may have begun with the ancestor of Bunocotyle + Saturnius and of Machidatrema and its sister group. The colonization of the Gulf of México and Caribbean Sea by some taxa may have taken place before the appearance of Panama Isthmus as a barrier between Pacific and Atlantic Oceans, approximately 4 million yr ago (Lessios, 1979). This radiation may have been associated with host switching from clupeids into the most diverse and widely distributed order of fish, the Perciformes. The capability of colonizing hosts other than clupeids may have permitted the bunocotylines to increase their geographic distribution.

The biogeographic history of the Bunocotylinae is complex, as would be expected from parasites of marine organisms, whose vagility can produce complex biogeographic patterns (Pérez-Ponce de León et al., 1996). That is the case of Pronocephalidae, primitive and primarily parasites of marine turtles; Pérez-Ponce de León and Brooks (1995) discovered a biogeographic distribution pattern suggesting a combination of vicariance and dispersion during a long period of time. Hoberg (1995) found that the role of intermediate hosts (zooplanktonic Crustacea) in the isolation or maintenance of gene flow (and consequently speciation) of tetrabothriid cestode populations in- 
habiting phocids in the Subarctic is insignificant, in contrast with that played by paratenic or definitive hosts (fish and phocids, respectively) with more restricted distribution, focused feeding habits, and established migratory patterns. Little is known about the life cycles of bunocotylines; presumably their intermediate hosts are copepods or chaetognaths as in other hemiurid groups (Køie, 1979; Køie and Lester, 1985). Only with the study of the biology of these worms and their intermediate and definitive hosts, in conjunction with species-level analyses of the various genera within the Bunocotylinae, will we be able to elucidate further the evolutionary history of this fascinating group.

\section{ACKNOWLEDGMENTS}

Funding for this study was provided by PADEP-UNAM proj. 3333-1994, proj. 3344-1996, and Fundación UNAM as a postdoctoral fellowship to V.L.R., PAPIIT-UNAM proj. IN201593 to G.P.P.L. and NSERC operating grant no. A7696 to D.R.B. We thank M. in S. Luis García-Prieto, CNHE, México, Ralph Lichtenfels and Patricia Pilitt, USNPC, Scott Gardner and Skip Sterner, HWML, Masaaki Machida, NSM, Tokyo, and Shunya Kamegai and Jun Araki, MPM for the loan of specimens. Special thanks to Fernando Marques for the drawing of Figure 2 and to 2 anonymous reviewers for their careful manuscript revision.

\section{LITERATURE CITED}

Brooks, D. R., S. M. Bandoni, C. M. Macdonald, and R. T. O'Grady. 1989. Aspects of the phylogeny of of the Trematoda Rudolphi, 1808 (Platyhelminthes: Cercomeria). Canadian Journal of Zoology 67: $2609-2624$.

- AND D. A. McLennan. 1993a. Parascript: Parasites and the language of evolution. Smithsonian Institution Press, Washington, D.C., $429 \mathrm{p}$.

, AND - 1993b. Macroevolutionary patterns of morphological diversification among parasitic flatworms (Platyhelminthes: Cercomeria). Evolution 47: 495-509.

, R. T. O'Grady, AND D. R. Glen. 1985. Phylogenetic analysis of the Digenea (Platyhelminthes: Cercomeria) with comments on their adaptive radiation. Canadian Journal of Zoology 63: 411-443.

GiBSON, D. I., AND R. A. BRAY. 1979. The Hemiuroidea: Terminology, systematics and evolution. Bulletin of the British Museum (Natural History) Zoology series 36: 35-146.

HenNig, W. 1966. Phylogenetic systematics. University of Illinois Press, Urbana, Illinois, $263 \mathrm{p}$.

HOBERG, E. P. 1995. Historical biogeography and modes of speciation across high-latitude seas of the Holarctic: Concepts for host-parasite coevolution among the Phocini (Phocidae) and Tetrabothriidae (Eucestoda). Canadian Journal of Zoology 73: 45-57.

KøIE, M. 1979. On the morphology and life-history of Derogenes varicus (Müller, 1784) Looss, 1901 (Trematoda: Hemiuridae). Zhurnal Parasitenkunde 59: 67-78.

, AND R. J. G. LESTER. 1985. Larval didymozoids (Trematoda) in fishes from Moreton Bay, Australia. Proceedings of the Helminthological Society of Washington 52: 196-203.

LEón-RĖGaGnon, V. 1997. Machidatrema n. gen. (Digenea: Hemiuridae: Bunocotylinae) and phylogenetic analysis of its species. Journal of Parasitology 84: 140-146.

, G. Pérez-Ponce de León, AND D. R. Brooks. 1996. Phylogenetic analysis of Opisthadena Linton, 1910 (Digenea: Hemiuridae: Bunocotylinae). Journal of Parasitology 82: 1005-1010. , - - AND L. García-PRIETo. 1997. Description of Heteroplectanum oliveri sp. n. (Monogenea: Diplectanidae) and comments on the helminth fauna of Kyphosus elegans (Perciformes: Kyphosidae) from Chamela Bay, México. Journal of the Helminthological Society of Washington 64: 9-16.

Lessios, H. A. 1979. Use of Panamanian sea urchins to test the molecular clock. Nature 280: 509-561.

Maddison, W. P., M. J. DonohuE, AND D. R. Maddison. 1984. Outgroup analysis and parsimony. Systematic Zoology 33: 83-103.

Pérez-Ponce de León, G., AND D. R. Brooks. 1995. Phylogenetic relationships of the genera of the Pronocephalidae Looss, 1902 (Digenea: Paramphistomiformes). Journal of Parasitology 81: 267277.

- L. García-Prieto, and V. León-Règagnon. 1996. Gastrointestinal digenetic trematodes of Olive Ridley's turtle (Lepidochelys olivacea) from Oaxaca, México. Taxonomy and infracommunity structure. Journal of the Helminthological Society of Washington 63: $76-82$.

SwOFFORD, D. 1993. Phylogenetic analysis using parsimony, Version 3.1.1. Illinois Natural History Survey, Urbana, Illinois, 257 p.

Tang, C. T., Z. M. Shi, CaO Hua, J. Z. Guan, and C. S. Pan. 1983. Trematodes from marine fishes from Fujian. I. Hemiurids. Acta Zootaxonomica Sinica 8: 33-42.

WATROUS, L. E., AND Q. WHEelER. 1981. The outgroup method of character analysis. Systematic Zoology 30: 1-11.

Wiley, E. O., D. Siegel-Causey, D. R. Brooks, and V. A. FunK. 1991. The compleat cladist: A primer of phylogenetic procedures. University of Kansas Museum of Natural History Press, Lawrence, Kansas, $158 \mathrm{p}$.

YamaGuTI, S. 1971. Synopsis of digenetic trematodes of vertebrates, Vol. I. Keigaku Publishing Co. Tokyo, Japan, 1,074 p. 